\title{
Electroencephalogram Evidence for Memory Suppression: A Systematic Review
}

\author{
Camila Arguello Dutra*, \\ Orcid.org/0000-0002-1620-0651 \\ Francielle Machado Beria ${ }^{1}$ \\ Orcid.org/0000-0003-2461-1968 \\ Isadora Silveira Ligório ${ }^{1}$ \\ Orcid.org/0000-0002-5503-238X \\ Gustavo Gauer ${ }^{1}$ \\ Orcid.org/0000-0002-8536-9493
}

${ }^{1}$ Universidade Federal do Rio Grande do Sul, Porto Alegre, RS, Brasil

\begin{abstract}
Understanding how people forget is one of the fundamental goals of the science of memory. Recent studies indicate that humans can voluntarily regulate awareness of unwanted memories by stopping the retrieval process that would ordinarily bring past experience into awareness. Event-related potential (ERP) research on memory retrieval reveals that electrophysiological effects with specific timing and scalp topography serve as markers of memory processes. This systematic review examines the literature regarding EEG alterations in memory suppression, highlighting their results on electrophysiological indicators. A systematic review from January 2007 to November 2017 was conducted using PubMed, Embase and ScienceDirect databases. As results, 12 studies were eligible for inclusion. Quantitative EEG can be a objective tool for studying the mechanisms involved in memory suppression. There is evidence that a parietal positivity around $400-800 \mathrm{~ms}$ after cue presentation is an ERP marker of conscious recollection during memory retrieval and a larger N2 deflection during retrieval suppression predicted greater suppression-induced forgetting.
\end{abstract}

Keywords: Event-related potential, electroencephalogram, memory suppression, inhibitory control, think/no-think.

* Mailing address: Universidade Federal do Rio Grande do Sul, Instituto de Psicologia, Rua Ramiro Barcelos, 2600, $2^{\circ}$ andar, sala 227, Porto Alegre -RS, Brasil, CEP 90035-003. E-mail: camiladutra.psico@gmail.com, fmberia@gmail.com, isa.ligorio@gmail.com and gusgauer@gmail.com

Support: Conselho Nacional de Desenvolvimento Científico e Tecnológico (CNPq); Universidade Federal do Rio Grande do Sul (UFRGS). 


\section{Evidências de Eletroencefalograma para Supressão de Memória: Uma Revisão Sistemática}

\section{Resumo}

Compreender como as pessoas esquecem é um dos objetivos fundamentais da ciência da memória. Estudos recentes indicam que os humanos podem voluntariamente regular a consciência de memórias indesejadas, interrompendo o processo de recuperação que normalmente levaria experiências passadas para a consciência. A pesquisa de Potenciais Relacionados a Eventos (PRE) sobre recuperação de memória revela que os efeitos eletrofisiológicos, com temporização específica e topografia do couro cabeludo, servem como marcadores de processos de memória. Esta revisão sistemática examina a literatura sobre alterações de EEG na supressão de memória, destacando seus resultados em indicadores eletrofisiológicos. Uma revisão sistemática de janeiro de 2007 a novembro de 2017 foi realizada usando as bases de dados PubMed, Embase e ScienceDirect. Como resultados, 12 estudos foram elegíveis para inclusão. Há evidência de que uma positividade parietal em torno de 400-800ms após a apresentação da pista é um marcador de PRE de lembrança consciente durante a recuperação da memória. Além disso, uma maior deflexão do componente $\mathrm{N} 2$ durante a supressão da recuperação sugeriu maior esquecimento induzido pela supressão.

Palavras-chave: Potencial relacionado a eventos, eletroencefalograma, supressão de memória, controle inibitório, think/no-think.

\section{Evidencia de Electroencefalograma para la Supresión de la Memoria: Una Revisión Sistemática}

\section{Resumen}

Comprender cómo las personas olvidan es uno de los objetivos fundamentales de la ciencia de la memoria. Estudios recientes indican que los humanos pueden regular voluntariamente la conciencia de los recuerdos no deseados al detener el proceso de recuperación que normalmente llevaría la experiencia pasada a la conciencia. La investigación de Potenciales relacionados con eventos (PRE) en la recuperación de la memoria revela que efectos electrofisiológicos sirven como marcadores de los procesos de memoria. Esta revisión sistemática examina la literatura sobre las alteraciones en EEG en la supresión de la memoria, destacando sus resultados en indicadores electrofisiológicos. Se realizó una revisión sistemática entre enero y noviembre de 2017 utilizando las bases de datos PubMed, Embase y ScienceDirect. Como resultados, 12 estudios fueron elegibles para su inclusión. Existe evidencia de que una positividad parietal alrededor de $400-800 \mathrm{~ms}$ después de la presentación de la señal es un marcador PRE de recolección consciente durante la recuperación de la memoria y una mayor deflexión de N2 durante la supresión de recuperación predijo un mayor olvido inducido por la supresión.

Palabras clave: Potencial relacionado con eventos, electroencefalograma, supresión de memoria, control inhibitorio, think/no-think.

"A retentive memory may be a good thing, but the ability to forget is the true token of greatness." Elbert Hubbard

One of the most relevant goals in the science of memory is to understand when, why, and how forgetting occurs. Apart from being a product of memory failure, forgetting may prove functional for cognitive processing when an individual reexperiences unpleasant or traumatic personal experiences in an uncontrolled fashion, as in intrusive. At the least, involuntarily evoked task-irrelevant and/or emotionally negative 
memories may compromise processing during cognitive tasks. Thus, intentionally avoiding and suppressing particular episodic representations, especially of negative events, may be an important ability in maintaining effective neurocognitive functioning (Anderson \& Huddleston, 2011). In practical terms, the intentional suppression of unwanted memories may be a successful strategy to forget what we prefer not to think about (Anderson \& Green, 2001). This systematic review aims to highlight electrophysiological indicators associated to memory suppression tasks extracted from articles that used "Think/ No-Think" (TNT) paradigm.

Research on memory has traditionally focused on passive factors that make people forget, such as the natural decay in memory traces. More recently, however, forgetting has been proposed as a result of factors besides the decay of memories over time, such as the accumulation of similar interfering experiences in memory, and changes in physical context that make it harder to recall the past (Anderson \& Hanslmayr, 2014). The former emphasis on passive factors fits the common assumption that forgetting is a negative outcome and, thus, any process underlying it must happen involuntarily. The TNT paradigm is as an experimental procedure that reproduces situations in which people ignore a memory that they prefer not to think about and try to keep it out of mind. Participants study cue-target word pairs and then are asked to exert control over retrieval during the experimental Think/No-Think phase. Most trials require them to remember the response whenever they see the reminder (think trials); however, for some reminders, participants are advised to avoid retrieving the response (nothink trials). It is essential to recognize that it is insufficient to avoid saying the response, because they must prevent the memory from entering awareness. Then, think and no-think trials are given either $0,1,8$, or 16 times. The final cued recall tests subjects' memory for the response words in two conditions (Anderson \& Green, 2001).

Studies using the Think/No-Think paradigm indicate that it is possible to forget unwanted memories by repeatedly attempting to repress them (Anderson \& Green, 2001; Anderson \& Levy, 2009; Anderson \& Huddleston, 2011). To understand how people stop retrieval, Anderson and Green (2001) developed a procedure modeled after the go/no-go task, which is a paradigm designed to investigate motor stopping. In a usual Go/No-Go paradigm, participants press a button as fast as possible whenever they see a letter appear on a screen, except when the letter is an $\mathrm{X}$, for which they must not press the button (Miller, Schäffer, \& Hackley, 1991). The inhibitory control over action is measured by their ability to retain the response. In order to see if stopping retrieval also engages inhibitory control, Anderson and Green (2001) adapted this procedure to develop the "Think/No-Think" paradigm.

Participants first learned the word pairs in the study phase, after which they practiced retrieving the target word aloud when presented with the cue for each pair. Once participants reached at least $50 \%$ performance in the test-feedback phase, they go to the Think/No-Think (TNT) phase. For think items (in green), participants retrieved the associated target. For no-think items (in red), they were asked to not remember the target. Following the TNT phase participants completed the test phase, in which they were presented with each cue word and were instructed to recall the corresponding target aloud.

In subsequent tests, memory for suppressed targets is lower when compared to baseline items that have been learned but not cued, before being either suppressed or retrieved between the study and test phases. The general finding from the results is a linear decline of retrieval for suppressed items (no-think trials). This memory impairment indicates/implies that inhibitory control may be voluntarily recruited to prevent unwanted memories from coming to mind. This large difference, known as the total control effect, demonstrates that is possible that intention to control retrieval modulates later memory and that there is a process that impairs the retention of memories when they are deliberately kept out of consciousness (Anderson \& Green, 2001; Anderson et al., 2004). 
1. Study Phase

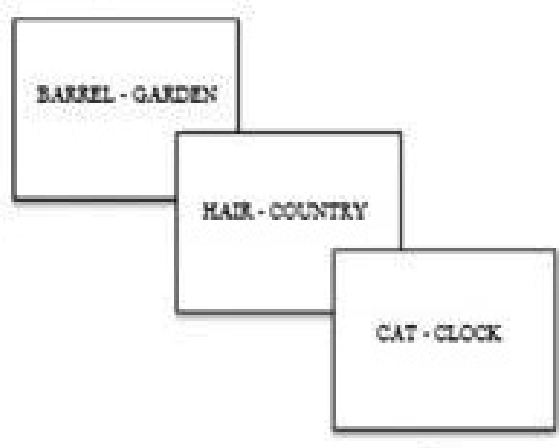

2. Test-Feedback/Criterion Phase

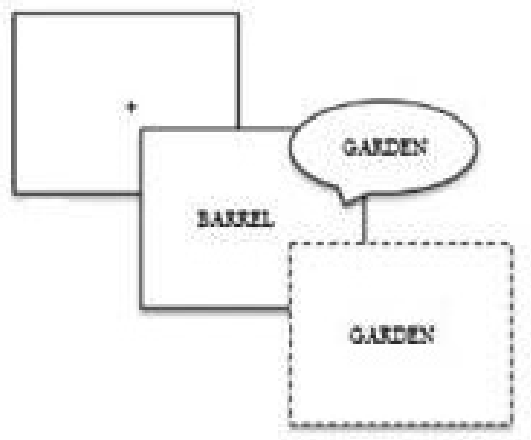

3. Think/No-Think Phase

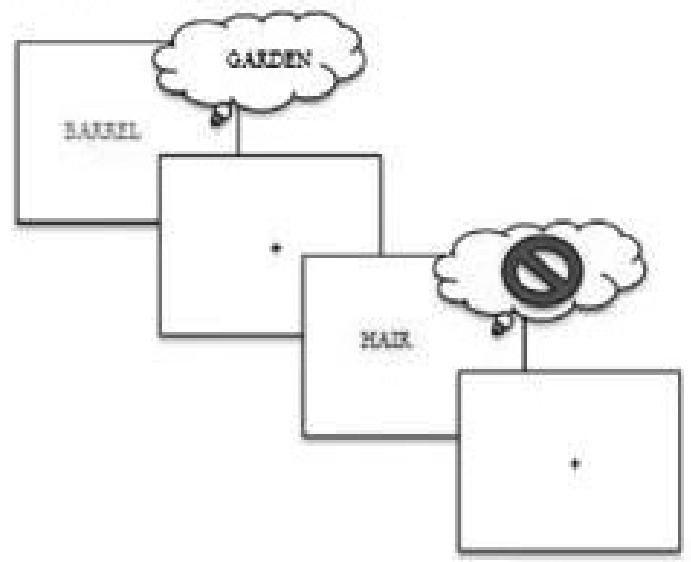

4. Test Phase

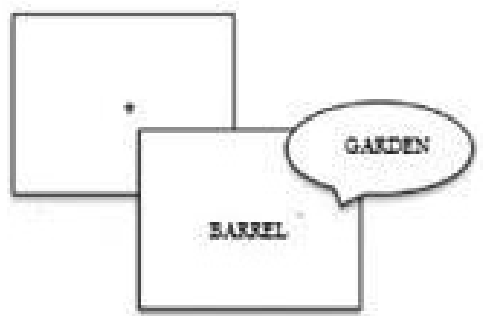

Figure 1. Experimental procedure.

Forgetting increases with the number of times a memory is suppressed (Anderson \& Green, 2001; Anderson \& Huddleston, 2011), which indicates that suppression yields cumulative effects. Moreover, the forgetting effect can be increased if time is given to participants in order to prepare for suppression (Hanslmayr, Leipold, \& Bäuml, 2010), indicating the importance of anticipatory processes. Also, suppression-induced forgetting arises with many stimuli, including word pairs, face-scene pairs (Depue, Curran, \& Banich, 2007), face-word pairs (Hanslmayr, Leipold, Pastötter, \& Bäuml, 2009), word-object pairs (Gagnepain, Henson, \& Anderson, 2014) and pairs comprising words and nonsense shapes (Hart \& Schooler, 2012).

In measuring physiological responses correlate to cognitive and behavioral processes, the electroencephalogram (EEG) has a chief advantage of having a very high temporal resolution (in the order of milliseconds), which favors precise synchronization between stimuli presentation, behavioral responses and hypothesized rapid information processing stages. It is also simpler and less expensive to implement in clinics and laboratories, when were compared it with other central techniques, such as positron emission tomography (PET) and functional magnetic resonance imaging (fMRI).

The main tool in real time examination of information processing employing EEG measurement are studies of Event-Related Potentials (ERPs). ERPs are synchronized activation of populations of neurons in response or preparation for events. That is, electrical potentials that are temporally associated with sensory, cognitive and motor events, and ERP components are peaks and valleys that oscillate 
in response to experimental manipulations (Rugg \& Coles, 1995). Memory suppression is reflected in a series of negative amplitude peaks that predict later forgetting, a reduction of the recollection-related late parietal positivity, and a modulation of ERP slow-waves at anterior frontal electrodes (Bergström, de Fockert, \& Richardson-Klavehn, 2009; Hanslmayr et al., 2009). The fact that memory suppression affects the ERP correlates of conscious recollection, occurring around $500 \mathrm{~ms}$ after onset of a memory cue was proven by previous Think/No-Think studies (Bergström et al., 2009; Mecklinger \& Jäger, 2009). This suggests that conscious retrieval is under strategic control and can be to intentionally avoid during suppression attempts.

The main goal of this review is to study the literature regarding EEG alterations (EventRelated Potential Components) in memory suppression tasks, by analyzing articles that used the TNT paradigm, highlighting their results on electrophysiological indicators.

\section{Method}

We conducted a systematic review of papers published from January 2007 to November 2017, using PubMed, Embase, and ScienceDirect databases. The search string "EEG" OR "electroencephalogram" OR "ERP" OR "event-related potential" AND "think/nothink" OR "memory suppression" OR "retrieval suppression" OR "intentional forgetting" was entered in the standard search field in all of the databases. In addition, for these searches of electronic databases, manual searches were also performed using the reference sections of published texts to find articles that were eligible for inclusion. Only papers written in the English language were analyzed. After removing duplicates, exclusion criteria were applied through seeking titles and abstracts. The following exclusion criteria were adopted: (a) theoretical and review papers, (b) studies with clinical population and (c) studies that did not use the think/no-think paradigm. Articles were initially selected according to their abstracts to identify the studies that effectively met the aims. Three independent judges performed the search, selection of papers and application of the exclusion criteria. The three judges discussed again when discordances were observed until all three agreed. In case of discordances, a fourth judge was consulted. An analysis table was constructed, with categories created a priori for the organization of the results. The three judges filled out the table. After removal of studies that met exclusion criteria, the remaining papers were fully read to identify the tasks employed in the studies and the results. The experimental tasks were analyzed according to the subjects and type of task. Overall results were organized into two categories: ERP results and summary of EEG spectral analysis.

\section{Results}

After performing searches of the aforementioned databases and removing duplicates, 121 articles were obtained. Figure 2 shows the steps of the electronic search that led to 12 articles being included in the systematic review. The exclusions based on the title and abstract $(n=73)$ were usually theoretical articles; articles that did not use TNT paradigm; studies with fMRI and publications in languages other than English. Of the remaining full-text articles, articles were excluded because of inclusion of psychiatric disorders $(n=5)$ and a lack of EEG $(n=6)$. The 12 studies selected are described below and grouped in two categories: eventrelated potential (ERP) studies and EEG spectral analysis studies.

\section{ERP Results}

The majority of the dimensional studies included in the review comprised ERP studies. There were twelve articles, nine of them were ERP studies and one performed both ERP and spectral analysis. The most common stimuli used in the ERP studies were word pairs. Table 1 describes the selected ERP studies. The results are summarized below. 

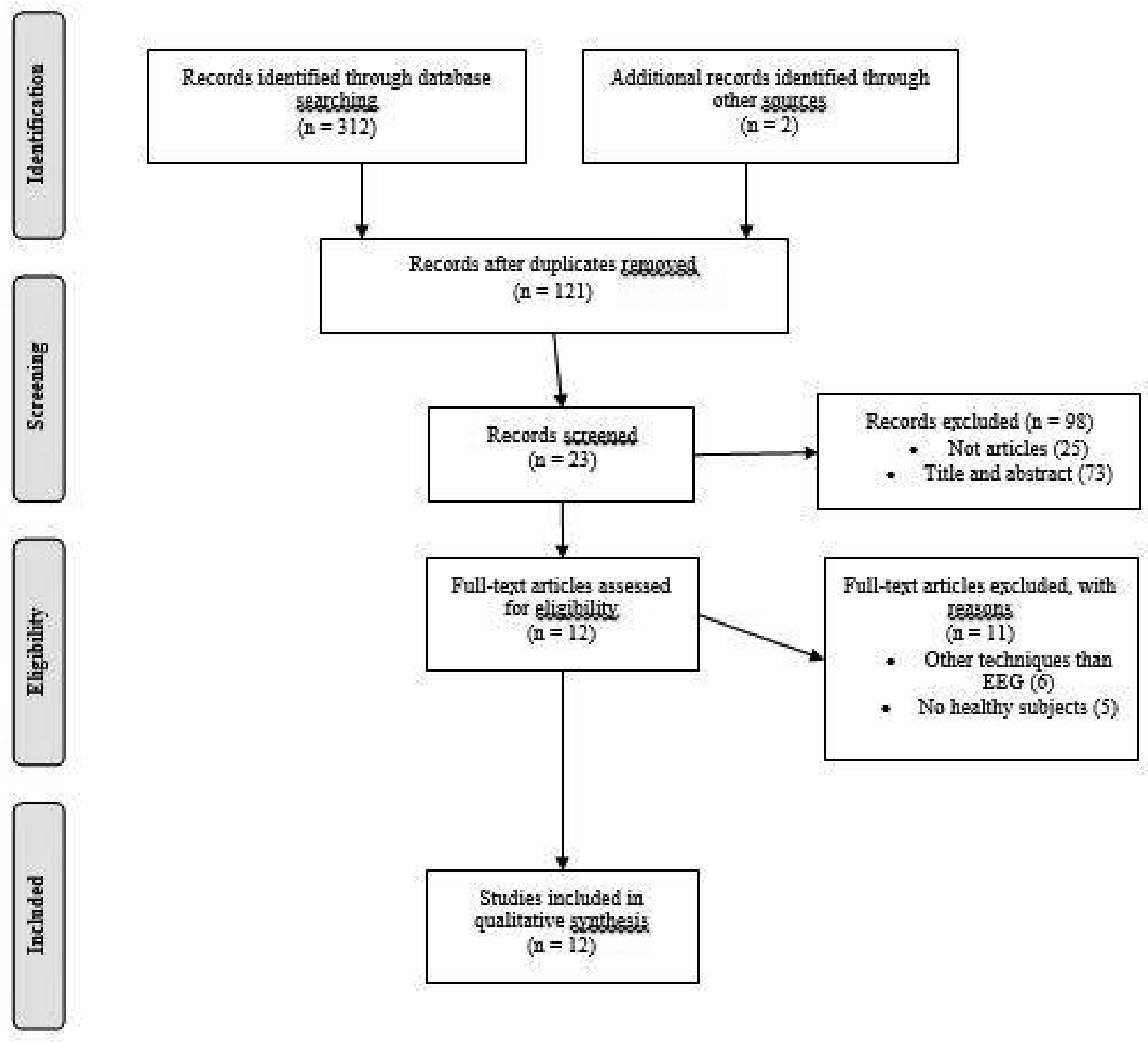

Figure 2. Summary of literature search, adapted from PRISMA (Moher, Liberati, Tetzlaff, \& Altman, 2009).

ERP findings based on TNT task revealed significant differences between think (T) responses and memory suppression in nothink (NT) condition. Early and late slow wave components during NT trials were found across frontal (early) and parietal (late) electrodes. These components were highly correlated, suggesting a possible role of top-down frontal control over parietal regions during the TNT task.

Mecklinger and Jäger (2009) found that an early P2 component and a parietal positivity were related to retrieval attempts and a centroparietal N2 component was associated with attempts to avoid memory retrieval. Also, successful stopping, identified by an experiment using a stop signal task, was associated with an enhanced stop signal $\mathrm{N} 2$ that showed a similar centro-parietal scalp distribution as the aforementioned N2 to NT trials.

Depue et al. (2013) found similar results regarding parietal positivity. The authors conducted a study with 29 undergraduate students using face-picture pairs as stimuli. Their ERP findings support an overall increase of the parietal effect for $\mathrm{T}$, as compared with NT and baseline trials. The suppression condition indicates reduced or down-modulated recollection processes during these trials.

Hanslmayr et al. (2009) found some results in the same direction. ERP effects were due to a decreased right frontal and left parietal positivity. They were positively related and predicted later forgetting. A T/NT repetition 
Table 1

Summary of ERP Results

\begin{tabular}{|c|c|c|c|}
\hline Study & Subjects & Task & Results \\
\hline $\begin{array}{l}\text { Waldhauser, } \\
\text { Lindgren, \& } \\
\text { Johansson, } 2012\end{array}$ & $\begin{array}{l}22 \text { healthy } \\
\text { right-handed } \\
\text { participants }\end{array}$ & $\begin{array}{l}\text { TNT paradigm, } \\
30 \text { word pairs }\end{array}$ & $\begin{array}{l}\text { More negative-going ERPs at frontal electrode } \\
\text { sites for NT condition. }\end{array}$ \\
\hline Depue et al., 2013 & $\begin{array}{l}29 \text { undergraduate } \\
\text { students }\end{array}$ & $\begin{array}{l}\text { TNT paradigm, } \\
44 \text { face-picture pairs }\end{array}$ & $\begin{array}{l}\text { Overall increase of the parietal effect for } \mathrm{T} \text {, as } \\
\text { compared with NT and baseline trials. }\end{array}$ \\
\hline $\begin{array}{l}\text { Streb, Mecklinger, } \\
\text { Anderson, Johanna, } \\
\text { \& Lass-Hennemann, } \\
2016\end{array}$ & $\begin{array}{l}21 \text { healthy } \\
\text { right-handed } \\
\text { participants }\end{array}$ & $\begin{array}{l}\text { TNT paradigm, } \\
84 \text { weakly related, } \\
\text { neutrally valenced } \\
\text { word pairs }\end{array}$ & $\begin{array}{l}\text { The NT condition showed greater negative } \\
\text { going ERPs at fronto-central electrode sites and } \\
\text { an N2 component between } 350 \text { and } 450 \mathrm{~ms} \text { over } \\
\text { frontal and central electrodes. }\end{array}$ \\
\hline $\begin{array}{l}\text { Hellerstedt, } \\
\text { Johansson, \& } \\
\text { Anderson, } 2016\end{array}$ & $\begin{array}{l}32 \text { healthy } \\
\text { right-handed } \\
\text { participants }\end{array}$ & $\begin{array}{l}\text { TNT paradigm, } \\
96 \text { semantically } \\
\text { unrelated word pairs }\end{array}$ & $\begin{array}{l}\text { A significantly greater negative slow wave } \\
\text { (NSW) effect for intrusions compared with } \\
\text { avoided retrievals in the 550-900ms. The LPP } \\
\text { was attenuated during retrieval suppression. }\end{array}$ \\
\hline Chen et al., 2012 & $\begin{array}{l}20 \text { healthy } \\
\text { right-handed } \\
\text { participants }\end{array}$ & $\begin{array}{l}\text { TNT paradigm, } \\
48 \text { face-picture pairs }\end{array}$ & $\begin{array}{l}\text { Memory suppression were associated with } \\
\text { changes during a time window of } 70-260 \mathrm{~ms} \text {, } \\
\text { such as } \mathrm{P} 1 \text { and } \mathrm{N} 2 \text {, mainly at the right inferior } \\
\text { frontal gyrus and occipital lobe. }\end{array}$ \\
\hline $\begin{array}{l}\text { Hanslmayr et al., } \\
2009\end{array}$ & $\begin{array}{l}24 \text { healthy } \\
\text { right-handed } \\
\text { participants }\end{array}$ & $\begin{array}{l}\text { TNT paradigm, } \\
54 \text { neutral faces } \\
\text { and } 54 \text { semantically } \\
\text { unrelated words }\end{array}$ & $\begin{array}{l}\text { ERP effects were due to a decreased right } \\
\text { frontal and left parietal positivity. Positivity in } \\
\text { the NT condition was selectively reduced over } \\
\text { right frontal and left parietal electrode sites. }\end{array}$ \\
\hline $\begin{array}{l}\text { Mecklinger } \\
\text { \& Jäger, } 2009\end{array}$ & $\begin{array}{l}24 \text { healthy } \\
\text { participants }\end{array}$ & $\begin{array}{l}\text { TNT paradigm, } \\
70 \text { weakly related } \\
\text { word pairs }\end{array}$ & $\begin{array}{l}\text { An early P2 component and a parietal positivity } \\
\text { were related to retrieval attempts and a centro- } \\
\text { parietal N2 component was associated with } \\
\text { attempts to avoid memory retrieval. The } \\
\text { parietal positivity was attenuated for NT trials } \\
\text { on learned items. Stop signal N2 showed a } \\
\text { similar centro-parietal scalp distribution as the } \\
\text { N2 to NT trials. }\end{array}$ \\
\hline $\begin{array}{l}\text { Bergström et al., } \\
2009\end{array}$ & $\begin{array}{l}21 \text { participants } \\
\text { in the Substitution } \\
\text { group and } 23 \\
\text { participants in the } \\
\text { Suppression group }\end{array}$ & $\begin{array}{l}\text { TNT paradigm, } \\
36 \text { weakly related } \\
\text { word pairs }\end{array}$ & $\begin{array}{l}\text { Only direct memory suppression reduced } \\
\text { centro-parietal positivity in the event-related } \\
\text { potentials (ERP) between } 300 \text { and } 600 \mathrm{~ms} \text { post- } \\
\text { stimulus. Only direct memory suppression } \\
\text { produced later inhibitory forgetting that was } \\
\text { predicted by an earlier negative. Thought } \\
\text { substitution produced later non-inhibitory } \\
\text { forgetting and had no effect on the ERP } \\
\text { correlate of recollection. }\end{array}$ \\
\hline
\end{tabular}

interaction analysis revealed that positivity in the NT condition was selectively reduced over right frontal and left parietal electrode sites with increasing trial repetitions.

Another study (Bergström, Velmans, de Fockert, \& Richardson-Klavehn, 2007) found significant ERP modulations that seem to reflect the strategic processing involved in voluntarily controlling recollection of a stored item-specific memory. In the later time-window, learned Think items elicited a larger late left parietal positivity than did not learned Think, learned No-Think, and not learned No-Think items.

Waldhauser and colleagues (2012) selected time windows based on previous findings. The only significant correlational pattern of 
ERP amplitude differences with later memory impairment was obtained between 300 and $350 \mathrm{~ms}$. Correlations were most pronounced across frontal, left hemispheric, and parietal electrodes.

A study conducted by Chen and colleagues (2012) using face-picture pairs as stimuli found that memory suppression processing for negative and neutral memories were associated with changes during components of a time window of $70-260 \mathrm{~ms}$, such as $\mathrm{P} 1$ and N2, mainly at the right inferior frontal gyrus. Suppression of aversive memories was associated with two major late ERP components between 380 and $800 \mathrm{~ms}$, primarily at the right medial and superior frontal gyrus.

A subsequent study of Bergström and colleagues (2009) directly contrasted thought substitution and direct suppression strategies. Only direct memory suppression reduced centro-parietal positivity in the ERP between 300 and $600 \mathrm{~ms}$ post-stimulus and produced later inhibitory forgetting. In contrast, thought substitution produced later non-inhibitory forgetting and had no effect on the ERP correlate of recollection.

Hellerstedt et al. (2016) study the ERP correlate of memory intrusion. The results indicated a significantly greater negative slow wave (NSW) effect for intrusions compared with avoided retrievals in the $550-900 \mathrm{~ms}$ time window. This effect may be related to memory intrusions and has been related to working memory maintenance.

Finally, Streb et al. (2016) tested the hypothesis that individual differences in retrieval suppression predict intrusive memories after trauma. The first ERP effect found consisted of an early negativity $(200 \mathrm{~ms})$ that was larger in the NT condition than in the $\mathrm{T}$ condition. The early negativity to NT trials had abroad bilateral distribution and co-occurred with a positive (P2) deflection to $\mathrm{T}$ trials.

\section{EEG Spectral Analysis Results}

A few works performed frequency domain analysis. Table 2 describes the selected spectral studies. Three studies employed time-frequency analysis in terms of oscillatory power and phase synchronization as measured by EEG, showing the dynamic oscillatory interaction of brain networks underlying voluntary memory suppression. The results of related frequency domain analysis are summarized in this session.

The results of the first study (Waldhauser, Bauml, \& Hanslmayr, 2014) indicated control effects through increased power in the theta (5-9 $\mathrm{Hz})$ frequency band in the medial and dorsolateral prefrontal cortex and higher longrange alpha $(10-14 \mathrm{~Hz})$ phase synchronization.

Table 2

Summary of EEG Spectral Analysis

\begin{tabular}{|c|c|c|c|}
\hline Study & Subjects & Task & Results \\
\hline $\begin{array}{l}\text { Waldhauser et al., } \\
2014\end{array}$ & $\begin{array}{l}24 \text { healthyright- } \\
\text { handedvolunteers }\end{array}$ & $\begin{array}{l}\text { TNT paradigm, } \\
54 \text { faces with } \\
\text { a neutral expression } \\
\text { semantically } \\
\text { unrelated words }\end{array}$ & $\begin{array}{l}\text { Control effects increased power in the } \\
\text { theta }(5-9 \mathrm{~Hz}) \text { frequency band in the } \\
\text { medial and dorsolateral prefrontal cortex } \\
\text { and higher long-range alpha }(10-14 \mathrm{~Hz}) \\
\text { phase synchronization }\end{array}$ \\
\hline $\begin{array}{l}\text { Ketz, O’Reilly, } \\
\text { \& Curran, } 2014\end{array}$ & $\begin{array}{l}30 \text { healthyright- } \\
\text { handedparticipants }\end{array}$ & $\begin{array}{l}\text { TNT paradigm, } \\
96 \text { word-image pairs }\end{array}$ & $\begin{array}{l}\text { Prominent theta oscillations ( } 3 \text { to } 8 \mathrm{~Hz} \text { ) in } \\
\text { controlled retrieval. Beta oscillations }(12 \\
\text { to } 30 \mathrm{~Hz} \text { ) were involved in high levels of } \\
\text { both controlled retrieval and suppression }\end{array}$ \\
\hline Depue et al., 2013 & 29 undergraduates & $\begin{array}{l}\text { TNT paradigm, } \\
44 \text { female face-picture } \\
\text { pairs }\end{array}$ & $\begin{array}{l}\text { Increases in both alpha and theta power } \\
\text { for NT as compared with T trials across } \\
\text { parietal electrodes }\end{array}$ \\
\hline
\end{tabular}


However, the second study (Ketz et al., 2014) used face and scenes as stimulus. The comparison between controlled retrieval vs. controlled suppression indicated more prominent theta oscillations ( 3 to $8 \mathrm{~Hz}$ ) in controlled retrieval. Beta oscillations (12 to $30 \mathrm{~Hz}$ ) were involved in high levels of both controlled retrieval and suppression.

Finally, the third study (Depue et al., 2013) employed pairs of a face with neutral expression and an emotionally negative picture. EEG analyses indicated increased alpha $(8-12 \mathrm{~Hz})$ and theta $(3-8 \mathrm{~Hz})$ oscillations across parietal electrodes for items to be suppressed. The analyses revealed increases in both alpha and theta power for NT as compared with $\mathrm{T}$ trials across parietal electrodes.

\section{Discussion}

Quantitative EEG can be a simple and objective tool for studying the mechanisms involved in memory suppression. Regarding the studies included in this systematic review, some interesting findings were obtained to answer the question if there is an EEG pattern for memory suppression.

\section{ERP Studies}

ERPs have been successfully employed in episodic memory tasks and can be used as markers of memory processes and the associated control mechanisms (Friedman \& Johnson, 2000; Mecklinger \& Jäger, 2009; Rugg \& Wilding, 2000). As a technique with high temporal resolution, ERPs have been used to investigate neurocognitive processes underlying memory suppression with the TNT paradigm. Evidences from research in the field indicates that the correlate of recollection is a positive ERP at parietal regions, accentuated in the left hemisphere that extends from 400 to $800 \mathrm{~ms}$ after stimulus onset (Friedman \& Johnson, 2000; Mecklinger, 2000; Smith, 1993; Smith \& Halgren, 1989). This positive component is larger for correctly recognized items from a previous learning phase than for correctly rejected new items.
There is evidence from previous studies that a parietal positivity around $400-800 \mathrm{~ms}$ after cue presentation is an ERP marker of conscious recollection during memory retrieval (Friedman \& Johnson, 2000; Rugg \& Coles, 1995; Rugg \& Curran, 2007). Although this parietal EM effect typically has a focal left-lateralised parietal distribution in recognition tasks, it sometimes has a broad bilateral centro-parietal distribution, and perhaps particularly so in cued recall tasks (Allan \& Rugg, 1997).

The present review found some similar results as previous literature. The largest differences between $\mathrm{T}$ and NT trials emerged at frontal and central sites (Bergström et al., 2009; Hanslmayr et al., 2009; Mecklinger \& Jäger, 2009; Streb et al., 2016; Waldhauser et al., 2012). The results have shown that the parietal EM effect can be substantially reduced by voluntarily stopping retrieval (Bergström et al., 2009; Hanslmayr et al., 2009; Mecklinger \& Jäger, 2009).

At least one electrophysiological correlate was consistently obtained in several studies: a fronto-centrally distributed N2 component, a negative-going ERP component which is consistently larger during retrieval suppression than during retrieval (Bergström et al., 2009; Bergström et al., 2007; Chen et al., 2012; Depue et al., 2007; Mecklinger \& Jäger, 2009; Streb et al., 2016; Waldhauser et al., 2012). Importantly, a larger N2 deflection during retrieval suppression predicted greater suppression-induced forgetting (Mecklinger \& Jäger, 2009). A correlation has also been demonstrated between the TNT N2 and the N2 observed in a motor stopping task (Bergström et al., 2009; Mecklinger \& Jäger, 2009), suggesting that both processes recruit general response inhibition mechanisms. There is possible to assume that some of the systems recruited to override proponent motor responses are also involved to suppress memory retrieval.

Another important common result was a positive ERP at parietal regions. The overall increase of parietal effect for $\mathrm{T}$ condition between 300 and $600 \mathrm{~ms}$ post-stimulus was related both in previous literature as in the present included 
articles (Bergström et al., 2009; Depue et al., 2013; Friedman \& Johnson, 2000; Hanslmayr et al., 2009; Mecklinger \& Jäger, 2009; Streb et al., 2016). Those finds indicates that there is a pattern from a ERP marker of conscious recollection during memory retrieval.

In summary, the results demonstrate an electrophysiological dissociation between ERP correlates of task-related strategic processes and the ERP correlate of item-specific conscious recollection versus avoidance of recollection. The most consistent findings include centroparietal positivity in the EEG between 300 and $600 \mathrm{~ms}$ post-stimulus, consistent with a reduction in the ERP correlate of recollection, and a larger N2 component deflection during suppression, that emerged around $200 \mathrm{~ms}$ post-stimulus, involved in control systems. Although the data presented here indicates a pattern in the ERP correlates of memory suppression, it is important to note that participant instructions and strategies to stop retrieval were not reported with details in most papers.

\section{EEG Spectral Analysis Studies}

In intracranial recordings, neural oscillations measure fluctuations in the local field potential and this reflects the excitatory and inhibitory input into different neuronal assemblies (Buzsaki \& Draguhn, 2004). However, in the EEG, these control mechanisms are evident in increased frontal theta oscillatory activity, that has been localized to medial and lateral prefrontal cortex regions during response conflict (Hanslmayr et al., 2009), memory interference (Staudigl, Hanslmayr, \& Bäuml, 2010), and memory suppression (Depue et al., 2013).

Top-down cognitive control in general and memory suppression also rely on enhanced fronto-parietal communication (Corbetta \& Shulman, 2002; Paz-Alonso, Blunge, Anderson, $\&$ Ghetti, 2013). That seems related to increased phase synchronization in the alpha frequency band (Sadaghiani et al., 2012; Sauseng et al., 2005). If they are taken together, these findings suggest that memory suppression should partially be mediated by increased prefrontal theta $(5-9 \mathrm{~Hz})$ oscillatory power and higher phase coupling in the alpha $(10-14 \mathrm{~Hz})$ band. Increased oscillatory power in the theta frequency band is commonly associated with successful memory retrieval (Nyhus \& Curran, 2010), which appears to be generated by hippocampocortical feedback loops is also a characteristic of retrieval and memory maintenance (Cashdollar et al., 2009). Increased theta frequency correlates with successful retrieval in all analyzed studies. Two of the three results (Depue et al., 2013; Waldhauser et al., 2014) also found an increased oscillatory power in the alpha frequency. Those results are consistent with previous literature and evidence, corroborating that the findings that memory suppression should be mediated by increased prefrontal theta oscillatory power and higher phase combination in the alpha band. However, it is important to note that the sample presented is small and more studies are needed to confirm the pattern of the findings.

\section{Conclusions}

In summary, the present systematic review results highlight the promising potential of centro-parietal positivity in the ERP between 300 and $600 \mathrm{~ms}$ post-stimulus as an important correlate of recollection, and a larger N2 component deflection around $200 \mathrm{~ms}$ poststimulus during suppression, as an important correlate involved in control systems. Theta and alpha measures also are acting as potential biomarkers of memory suppression. However, there is more work needed to confirm if these EEG parameters are effective as a pattern from a ERP marker of conscious recollection during memory retrieval.

\section{Limitations}

One limitation of the present systematic review concerns the use of three electronic databases, even though they are the principal databases used in the field. Moreover, the search was limited to articles published in English. Consequently, this review provides no information regarding unpublished studies or 
studies published in other languages. The search was restricted to articles published since 2007. Another limitation was the heterogeneity of the studies, which made it impossible to perform a meta-analysis. The conclusions are based on a qualitative analysis of the studies. Future studies should try to include similar variables, whenever possible, to allow for greater comparability of findings.

\section{Authors' Contributions}

Substantial contribution in the concept and design of the study: Gustavo Gauer e Camila Arguello Dutra.

Contribution to data collection: Camila Arguello Dutra, Francielle Machado Beria, Isadora Silveira Ligório.

Contribution to data analysis and interpretation: Camila Arguello Dutra, Francielle Machado Beria, Isadora Silveira Ligório e Gustavo Gauer.

Contribution to manuscript preparation: Camila Arguello Dutra.

Contribution to critical revision, adding intelectual content: Gustavo Gauer e Camila Arguello Dutra.

\section{Conflicts of interest}

The authors declare that they have no conflict of interest related to the publication of this manuscript.

\section{References}

Allan, K., \& Rugg, M. D. (1997). An event-related potential study of explicit memory on tests of cued recall and recognition. Neuropsychologia, 35(4), 387-397.

Anderson, M. C., \& Green, C. (2001). Suppressing unwanted memories by executive control. Nature, 410, 366-369.

Anderson, M. C., \& Hanslmayr, S. (2014). Neural mechanisms of motivated forgetting. Trends in Cognitive Sciences, 18, 279-292. doi: 10.1016/j. tics.2014.03.002

Anderson, M. C., \& Huddleston, E. (2011). Towards a cognitive and neurobiological model of motivated forgetting. In R. F. Belli (Ed.), True and False Recovered Memories: Toward a reconciliation of the debate (pp. 53-120). New York: Springer.

Anderson, M. C., \& Levy, B. J. (2009). Suppressing unwanted memories. Current Directions in Psychological Science, 18, 189-194.

Anderson, M. C., Ochsner, K. N., Kuhl, B., Cooper, J., Robertson, E., Gabrieli, S. W., Glover, G. H., \& Gabrieli, J. D. E. (2004). Neural systems underlying the suppression of unwanted memories. Science, 303, 232-235.

Bergström, Z. M., de Fockert, J. W., \& RichardsonKlavehn, A. (2009). ERP and behavioural evidence for direct suppression of unwanted memories. NeuroImage, 48(4), 726-737.

Bergström, Z. M., Velmans, M., de Fockert, J., \& Richardson-Klavehn, A. (2007). ERP evidence for successful voluntary avoidance of conscious recollection. Brain Research, 1151, 119-133.

Buzsaki, G., \& Draguhn, A. (2004). Neuronal oscillations in cortical networks. Science, 304(5679), 1926-1938.

Cashdollar, N., Malecki, U., Rugg-Gunn, F. J., Duncan, J. S., Lavie, N., \& Duzel, E. (2009). Hippocampus-dependent and independent thetanetworks of active maintenance. Proceedings of the National Academy of Science USA, 106(48), 20493-20498. doi: 10.1073/pnas.0904823106

Chen, C., Liu, C., Huang, R., Cheng, D., Wu, H., Xu, P., Mai, X., \& Luo, Y. J. (2012). Suppression of aversive memories associates with changes in early and late stages of neurocognitive processing. Neuropsychologia, 50(12), 2839-2848. doi: 10.1016/j.neuropsychologia.2012.08.004

Corbetta, M., \& Schulman, G. L. (2002). Control of goal-directed and stimulus-driven attention in the brain. Nature Reviews Neuroscience, 3, 201215. doi: $10.1038 / \mathrm{nrn} 755$

Depue, B., Curran, T., \& Banich, M. T. (2007). Prefrontal regions orchestrate suppression of emotional memories via a two-phase process. Science, 317, 215-219. doi: 10.1126/ science. 1139560

Depue, B., Ketz, N., Mollison, M. V., Nyhus, E., Banich, M. T., \& Curran, T. (2013). ERPs and Neural oscillations during volitional suppression of memory retrieval. Journal of Cognitive Neuroscience, 25, 1624-1633. doi: 10.1162/ jocn_a_00418 
Friedman, D., \& Johnson, J. R. (2000). Event-related potential (ERP) studies of memory encoding and retrieval: A selective review. Microscopy Research Technique, 51, 6-28.

Gagnepain, P., Henson, R. N., \& Anderson, M. C. (2014). Suppressing unwanted memories reduces their unconscious influence via targeted cortical inhibition. Proceedings of the National Academy of Science USA, 111(13), E1310-E1319. doi: 10.1073/pnas.1311468111

Hanslmayr, S., Leipold, P., \& Bäuml, K. H. (2010). Anticipation boosts forgetting of voluntarily suppressed memories. Memory, 18, 252-257. doi: 10.1080/09658210903476548

Hanslmayr, S., Leipold, P., Pastötter, B., \& Bäuml, K. H. (2009). Anticipatory signatures of voluntary memory suppression. Journal of Neuroscience, 29(9), 2742-2747. doi: 10.1523/ JNEUROSCI.4703-08.2009

Hart, R. E., \& Schooler, J. W. (2012). Suppression of novel stimuli: Changes in accessibility of suppressed nonverbalizable shapes. Consciousness and Cogition, 21(3), 1541-1546. https://doi.org/10.1016/j.concog.2012.06.005

Hellerstedt, R., Johansson, M., \& Anderson, M. C. (2016). Tracking the intrusion of unwanted memories into awareness with event-related potentials. Neuropsychologia, 89, 510-523. doi: 10.1016/j.neuropsychologia.2016.07.008

Ketz, N., O’Reilly, R. C., \& Curran, T. (2014). Classification aided analysis of oscillatory signatures in controlled retrieval. Neuroimage, 85, 749-760. doi: 10.1016/j. neuroimage.2013.06.077

Mecklinger, A. (2000). Interfacing mind and brain: A neurocognitive model of recognition memory. Psychophysiology, 37(05), 565-582.

Mecklinger, A., \& Jäger, T. (2009). Episodic memory storage and retrieval: Insights from electrophysiological measures. Neuroimaging and Psychological Theories of Human Memory, 357-382. doi: 10.1093/ acprof:oso/9780199217298.003.0020

Miller, J., Schäffer, R., \& Hackley, S. A. (1991). Effects of preliminary information in a Go versus No-go task. Acta Psychologica, 76(3), 241-292.

Moher, D., Liberati, A., Tetzlaff, J., \& Altman, D. G. (2009). Preferred reporting items for systematic reviews and meta-analyses: The PRISMA statement. PLoS Medicine, 6(7), e1000097. doi: 10.1371/journal.pmed.1000097

Nyhus, E., \& Curran, T. (2010). Functional role of gamma and theta oscillations in episodicmemory. Neuroscience \& Biobehavioral Reviews, 34(7), 1023-1035. doi: 10.1016/j. neubiorev.2009.12.014

Paz-Alonso, P. M., Blunge, S. A., Anderson, M. C., $\&$ Ghetti, S. (2013). Strength of coupling within a mnemonic control network differentiates those who can and cannot suppress memory retrieval. Journal of Neuroscience, 33(11), 5017-5026. doi: 10.1523/JNEUROSCI.3459-12.2013

Rugg, M. D., \& Coles, M. G. H. (1995). Electrophysiology of Mind. Oxford, UK: Oxford University Press.

Rugg, M. D., \& Curran, T. (2007). Event-related potentials and recognition memory. Trends in Cognitive Sciences, 11(6), 251-257.

Rugg, M. D., \& Wilding, E. L. (2000). Retrieval processing and episodic memory. Trends in Cognitive Sciences, 4(3), 108-115.

Sadaghiani, S., Scheeringa, R., Lehongre, K., Morillon, B., Giraud, A., D’Esposito, M., \& Kleinschmidt, A. (2012). Alpha-band phase synchrony is related to activity in the fronto-parietal adaptive control network. Journal of Neuroscience, 32(41), 14305-14310. doi: 10.1523/JNEUROSCI.1358-12.2012

Sauseng, P., Klimesch, W., Doppelmayr, M., Pecherstorfer, T., Freunberger, R., \& Hanslmayr, S. (2005). EEG alpha synchronization and functional coupling during top-down processing in a working memory task. Human Brain Mapping, 26, 148-155.

Smith, M. E. (1993). Neurophysiological manifestations of recollective experience during recognition memory judgements. Journal of Cognitive Neuroscience, 5, 1-13.

Smith, M. E., \& Halgren, E. (1989). Dissociation of recognition memory components following temporal lobe lesions. Journal of Experimental Psychology: Learning, Memory, and Cognition, 15(1), 50

Staudigl, T., Hanslmayr, S., \& Bäuml, K. H. T. (2010). Theta oscillations reflect the dynamics of interference in episodic memory retrieval. Journal of Neuroscience, 30(34), 11356-11362. doi: 10.1523/JNEUROSCI.0637-10.2010 
Streb, M., Mecklinger, A., Anderson, M. C., Johanna, L. H., \& Michael, T. (2016). Memory control ability modulates intrusive memories after analogue trauma. Journal of Affective Disorders, 192, 134-142. doi: 10.1016/j.jad.2015.12.032

Waldhauser, G. T., Bäuml, K. H. T., \& Hanslmayr, S. (2014). Brain oscillations mediate successful suppression of unwanted memories. Cerebral Cortex, 25(11), 4180-4190. doi: 10.1093/cercor/ bhu 138
Waldhauser, G. T., Lindgren, M., \& Johansson, M. (2012). Intentional suppression can lead to a reduction of memory strength: Behavioral and electrophysiological findings. Frontiers in Psychology, 3, 401. doi: 10.3389/ fpsyg.2012.00401

Received: 08/01/2018

${ }^{\text {st }}$ revision: $17 / 05 / 2018$

Accepted: 04/07/2018 distribution, and reproduction in any medium, provided you give appropriate credit to the original author(s) and the source, provide a link to the Creative Commons license, and indicate if changes were made. 